\title{
Genetic Diversity for Quality Traits and Seed Yield in Pigeonpea [Cajanus cajan (L.) Millsp.]
}

\author{
Yogesh, Ravika*, Rajesh Yadav, Nisha Kumari and Suman \\ Department of Genetics and Plant Breeding, CCS Haryana Agricultural University, \\ Hisar-125004, India \\ *Corresponding author
}

\begin{abstract}
A B S T R A C T
Keywords

Genetic diversity, Pigeonpea, Cluster analysis, Seed quality

Article Info

Accepted:

20 May 2019

Available Online:

10 June 2019

A set of 75 pigeonpea genotypes were evaluated during kharif 2017-18, to determine the genetic divergence among these genotypes for 17 seed yield and quality characters and to identify divergent parents. UPGMA method of Hierarchical Cluster analysis used with City Block distances grouped these genotypes into ten distinct clusters comprising of one to twenty genotypes. Maximum inter cluster distance was observed between cluster II and VIII followed by cluster II and VI and cluster II and IX. Genotype of cluster II showed highest mean values for plant height, methionine content and tryptophan content whereas, genotypes in cluster VIII showed highest mean values for number of pods, number of seeds and biological yield. Hybridization between the genotypes belonging to these distinct clusters is expected to produce desirable transgressive segregants. Genotypes AL 1404, AL 1356-04, ICPL 89011-1, AL 668 and AH 09-38 were found promising for both yield and quality traits and also belonged to distant clusters hence can be utilized for future pigeonpea improvement programmes.
\end{abstract}

\section{Introduction}

Pigeonpea [Cajanus cajan (L.) Millsp.] is the fourth most important pulse crop of the world and second most important of India which is its largest grower and producer sharing about $80 \%$ of its area and production. It is a diploid $(2 n=22)$ often cross pollinated $(20-70 \%)$ major grain legume crop and generally known as arhar, red gram and tur. It is a widely adapted, drought tolerant multiple use pulse crop cultivated throughout the semi arid tropics and subtropics (Saxena et al., 2010). It is of considerable importance in areas of
South Asia (mainly on the Indiansubcontinent), Africa, the Caribbean and Latin America, where it is a prominent source of protein in the human diet (Vijayalakshmi $e t$ al., 2013), as well as wood for fuel and light duty structural applications such as thatch for roofing. It is a promising source for protein, water soluble vitamins especially thiamine, riboflavin, niacin and choline (Sinha, 1977), carbohydrates 53.23\% (Aruna and Devindra, 2016), crude fiber, fat, trace elements (Saxena et al., 2010 ) and some minerals such as potassium, phosphorus, calcium and magnesium (Nwokolo, 1986). Among amino 
acids, lysine concentration is high (7.79 $\mathrm{g} / 16 \mathrm{gN}$ ) in pigeonpea seed, but it is deficient in the sulphur containing amino acids cystine and methionine $(0.24$ and $0.16 \mathrm{~g} / 100 \mathrm{~g}$ protein, respectively) as per reports of Saxena et al., (2008).

In India, though pigeonpea occupies second place among pulses after chickpea yet its productivity is stagnant since almost two decades due to many reasons major being different biotic and abiotic stresses and narrow genetic base which may be because of the frequent use of the same parents and their derivatives in breeding programmes (Kumar et al., 2004). Pigeonpea germplasm represents a diverse set of landraces and heterogeneous feral forms that are adapted to various agroecological settings (Saxena, 2008). Despite extensive phenotypic diversity, molecular evidence from Simple Sequence Repeats (Odeny et al., 2007) and Diversity Array Technology (Yang et al., 2006) suggests very low genetic diversity within cultivated pigeonpea when compared to its wild relatives. Hence the search for new, diverse and useful genetic stocks and their precise evaluation for improvement programmes is never ending. The magnitude of genetic variability and diversity can determine the pace and quantum of genetic improvement through selection or hybridization followed by selection. The assessment of genetic diversity is important not only for crop improvements programmes but also efficient management and conservation of germplasm resources. Detailed evaluation of germplasm for good agronomy and quality and tolerance to biotic and abiotic stresses helps in the identification of superior genetic stocks and subsequently for their utilization in breeding programmes (Rana et al., 2016). Further inclusion of all the component traits in selection scheme for intricate characters like yield and quality is impractical because of apparent reasons, knowledge of association of various traits is fundamental in formulating efficient breeding programme.

\section{Materials and Methods}

The field experiment was conducted at research area of Pulses Section and the biochemical analysis of seed samples were carried out in Quality Lab of Oilseed Section, Department of Genetics and Plant Breeding, CCS Haryana Agricultural University, Hisar. Seventy five pigeonpea genotypes of diverse origin (Table 1) were sown in Randomized Block Design with three replications during kharif season 2017-18. Each entry was sown in single row of $4 \mathrm{~m}$ length with $60 \times 15 \mathrm{~cm}$ spacing. From every genotype, five competitive plants were randomly selected for recording of data for 17 seed yield and quality characters viz. Days to $50 \%$ flowering, Days to maturity, Plant height $(\mathrm{cm})$, Number of branches per plant, Number of pods per plant, Biological yield per plant (g), Seed yield per plant (g), Harvest index (\%), 100 seed weight (g), Number of seeds per pod, Crude protein $(\%)$, Ash content $(\%)$, Fat content (\%), Crude fiber content $(\%)$, Methionine content $(\mathrm{mg} / \mathrm{g}$ of protein), Tryptophan content (mg/g of protein) and Tannin content (mg/g). Unweighted Pair Group Method using Arithmetic Averages (UPGMA) method of Hierarchical Cluster analysis was used with City Block distances to classify the genotypes for their genetic diversity on the basis of 17 yield and quality variables.

\section{Results and Discussion}

The germplasm is the reservoir of genetic diversity, which is exploited to meet the changing needs for developing improved varieties of a crop. It is also important that considerable variability for economic traits must exist in the germplasm for profitable exploitation following recombination during selection. The need of parental diversity in 
optimum magnitude to obtain superior genotypes for recovering transgressive segregants has also been repeatedly emphasized. Earlier workers considered distance in place of origin as index of genetic diversity and used it for selection of parents for hybridization. However, the genetic diversity of selected parents is not always based on factors such as geographic diversity or place of release or ploidy level (Durga et al., 2005; Dwevedi and Gaibriyal, 2009; Sreelakshmi et al., 2010 and Yadav et al., 2010). Thus, for characterization of germplasm for genetic divergence and selection for suitable diverse genotypes should be based on sound statistical procedures, such as hierarchical cluster analysis. These procedures characterize genetic divergence using the criteria of similarity or dissimilarity based on the aggregate effect of a number of agronomically important characters. Unweighted Pair Group Method Using Arithmetic Averages (UPGMA) method of hierarchical cluster analysis was used with City Block distances to classify the 75 pigeonpea genotypes for their genetic diversity on the basis of 17 yield and quality variables.

The hierarchical cluster analysis grouped the 75 pigeonpea genotypes into ten distinct clusters (Table 2 and Fig. 1). The discrimination of germplasm lines into so many discrete clusters indicated presence of substantial amount of diversity in the material evaluated. Maximum number of genotypes were grouped in cluster I (20 genotypes) followed by cluster IV (18 genotypes), cluster VI (12 genotypes), cluster VIII and IX (six genotypes each), cluster III and V (five genotypes each) and cluster II, VII and X (one genotype each). Earlier workers have also reported existence of high degree of genetic diversity in pigeonpea material (Reddy et al.,
2015, Sreelakshmi et al., 2011, Birhan et al., 2013, Pandey et al., 2013 and Rao et al., 2013). Presence of substantial genetic divergence among the germplasm line screened in present investigation suggested that this material might serve as good source for selection of diverse parents for hybridization programme aimed at isolating desirable combination for seed yield as well as other characters.

In the present study, the maximum intra cluster distance was shown by cluster I followed by cluster IV and cluster VI, while, maximum inter cluster distance were showed between cluster II and cluster VIII followed by cluster II and cluster VI and cluster II and IX (Table 3) The estimates of average intra and inter cluster distances for ten clusters revealed that the genotypes of the same cluster have little genetic divergence from each other with respect to aggregate effects of 17 characters under study while much more genetic diversity was observed between the genotypes of different clusters. Since high or optimum genetic divergence is required between the parents of hybridization plan for obtaining high frequency of desirable recombinants with favourable chances of obtaining good segregants in the segregating generations it would be logical to attempt crosses between the diverse genotypes belonging to clusters separated by large intercluster distances. The above findings are broadly in agreement with report of (Sreelakshmi et al., 2011; Birhan et al., 2013; Pandey et al., 2013; Rao et al., 2013; Shweta and Srivastava, 2013; Reddy et al., 2015; Navneet et al., 2017).

The cluster means for the 17 quantitative traits studied in genotypes of pigeonpea revealed considerable differences among all the clusters (Table 4). Cluster wise means for the characters studied were presented. 
Table.1 List of genotypes included in the study

\begin{tabular}{|c|c|c|c|c|c|}
\hline Sr. No. & Genotype & Sr. No. & Genotype & Sr. No. & Genotype \\
\hline $\mathbf{1}$ & AH06-4 & 26 & AH06-9 & 51 & AL1356-04 \\
\hline $\mathbf{2}$ & H01-22 & 27 & AL1577 & 52 & Pusa855-2 \\
\hline $\mathbf{3}$ & AH06-5 & 28 & AL1581 & 53 & CORG9701 \\
\hline $\mathbf{4}$ & AL442 & 29 & AL1590 & 54 & EKD-12 \\
\hline $\mathbf{5}$ & H03-41 & 30 & AL1508 & 55 & AH09-8 \\
\hline $\mathbf{6}$ & AL601 & 31 & ICPL87 & 56 & AH09-13 \\
\hline $\mathbf{7}$ & Pusa2008-2 & 32 & H05-15 & 57 & ICPL91039 \\
\hline $\mathbf{8}$ & AL668 & 33 & AH09-44 & 58 & Pusa945 \\
\hline $\mathbf{9}$ & AL1685 & 34 & AL1455 & 59 & AH09-247 \\
\hline $\mathbf{1 0}$ & AH06-2 & 35 & Vmbn-1 & 60 & A293-4 \\
\hline $\mathbf{1 1}$ & AL1313 & 36 & AL1484 & 61 & ICPL91021 \\
\hline $\mathbf{1 2}$ & AL1389 & 37 & AH10-27 & 62 & ICPL92040 \\
\hline $\mathbf{1 3}$ & AL1401 & 38 & H93-22 & 63 & Scl-285 \\
\hline $\mathbf{1 4}$ & AL1404 & 39 & H01-8 & 64 & ICPL89011-1 \\
\hline $\mathbf{1 5}$ & AL1416 & 40 & AH10-13 & 65 & ICPL91008 \\
\hline $\mathbf{1 6}$ & AL1417 & 41 & H04-21 & 66 & AL1354-2-2 \\
\hline $\mathbf{1 7}$ & AL1419 & 42 & AL609 & 67 & H05-06 \\
\hline $\mathbf{1 8}$ & AL1421 & 43 & AH10-08 & 68 & AH09-18 \\
\hline $\mathbf{1 9}$ & AL1425 & 44 & ICPL28323 & 69 & B-17200 \\
\hline $\mathbf{2 0}$ & AL1431 & 45 & Harsana & 70 & AH05-65 \\
\hline $\mathbf{2 1}$ & AL1434 & 46 & D36 & 71 & AH09-38 \\
\hline $\mathbf{2 2}$ & AL1439 & 47 & H9343 & 72 & UPAS120 \\
\hline $\mathbf{2 3}$ & AL1444 & 48 & PA421 & 73 & Manak \\
\hline $\mathbf{2 4}$ & AL1452 & 49 & AH09-06 & 74 & Paras \\
\hline $\mathbf{2 5}$ & AL1453 & 50 & AL1366-1 & 75 & PAU881 \\
\hline
\end{tabular}

Table.2 Cluster membership and number of genotypes in each cluster of pigeonpea

\begin{tabular}{|c|l|c|}
\hline Cluster No. & \multicolumn{1}{|c|}{ Name of Genotypes } & No. of Genotypes \\
\hline I & $\begin{array}{l}\text { AH06-4, AH06-5, AL1685, AL1439, AL1444, AL1452, AH 10-27, AH 10-13, HARSANA, D- } \\
\text { 36, AL 1366-1, AL 1356-04, PUSA 855-2, CORG 9701, AH09-8, AH 09-13, PUSA 945, ICPL } \\
\text { 92040, ICPL 89011-1, MANAK }\end{array}$ & 20 \\
\hline II & H01-22 & 1 \\
\hline III & AL 442, AL1577, H05-15, AH09-18, B-17200 & 5 \\
\hline IV & $\begin{array}{l}\text { H03-41, AL 668, AL 1401, AL 1417, AL 1434, AL 1453, AL 609, ICPL 28323, AH09-06, AH09- } \\
\text { 247, A293-4, ICPL 91021, SCL-285, AL1354-2-2, AH05-65, UPAS 120, PARAS, PAU 881 }\end{array}$ & 18 \\
\hline V & AL 601, AL 1419, AL 1421, AH 06-9, EKD-12 & 5 \\
\hline VI & PUSA2008-2, AH06-2, AL1313, AL1581, ICPL 87, AH09-44, AL 1455, VMBN-1, AL 1484, & 12 \\
\hline VII & H01-8, AH 10-08, ICPL 91008 & 1 \\
\hline VIII & AL 1389 1404, AL 1431, AL 1508, H93-22, H93-43, AH09-38 & 6 \\
\hline IX & AL 1416, AL 1590, H04-21, PA 421, ICPL 91039, H05-06 & 6 \\
\hline X & AL 1425 & 1 \\
\hline Total & & 75 \\
\hline
\end{tabular}


Table.3 Inter and intra - cluster distances in pigeonpea

\begin{tabular}{|l|c|c|c|c|c|c|c|c|c|c|}
\hline $\begin{array}{l}\text { Cluster } \\
\text { No. }\end{array}$ & I & II & III & IV & V & VI & VII & VIII & IX & X \\
\hline I & 59.73 & & & & & & & & & \\
\hline II & 91.828 & - & & & & & & & & \\
\hline III & 128.458 & 183.262 & 47.782 & & & & & & & \\
\hline IV & 136.886 & 196.792 & 99.17 & 58.191 & & & & & & \\
\hline V & 98.164 & 160.872 & 86.456 & 82.011 & 51.003 & & & & & \\
\hline VI & 196.48 & 254.636 & 103.677 & 94.296 & 135.072 & 57.269 & & & & \\
\hline VII & 143.433 & 167.963 & 181.608 & 117.733 & 142.642 & 131.927 & - & & & \\
\hline VIII & 242.836 & 305.746 & 145.505 & 139.129 & 178.281 & 84.229 & 156.12 & 45.88 & & \\
\hline IX & 179.27 & 245.287 & 134.239 & 87.489 & 121.263 & 82.856 & 108.198 & 104.285 & 48.66 & \\
\hline $\mathbf{X}$ & 106.776 & 116.831 & 116.885 & 142.556 & 106.235 & 187.812 & 214.784 & 231.516 & 184.354 & - \\
\hline
\end{tabular}

Diagonal- Intra-cluster distances, Off-diagonal- Inter-cluster distances

Table.4 Cluster means for different characters in pigeonpea

\begin{tabular}{|c|c|c|c|c|c|c|c|c|c|c|c|c|c|c|c|c|c|}
\hline Characters & DF & DM & PH & NB & NP & BIOL & SY & SW & NS & HI & Ash & Fat & CF & CP & Met & Try & Tan \\
\hline I & 86.2 & 131.5 & 254.0 & 12.9 & 165.6 & 172.1 & 24.7 & 6.5 & 3.8 & 14.5 & 3.7 & 5.1 & 5.7 & 20.5 & 0.9 & 0.015 & 0.518 \\
\hline II & 87.3 & 132.3 & 265.2 & 13.9 & 138.4 & 149.3 & 21.4 & 6.4 & 3.0 & 14.4 & 5.3 & 2.2 & 5.5 & 19.7 & 1.8 & 0.027 & 2.000 \\
\hline III & 86.8 & 132.1 & 257.2 & 14.9 & 233.7 & 196.5 & 29.2 & 6.4 & 4.0 & 14.9 & 3.8 & 5.8 & 5.3 & 20.4 & 1.0 & 0.022 & 0.900 \\
\hline IV & 86.4 & 132.6 & 253.8 & 15.0 & 205.8 & 232.5 & 29.6 & 6.3 & 3.9 & 12.8 & 3.9 & 5.0 & 5.7 & 20.9 & 0.9 & 0.017 & 0.746 \\
\hline V & 87.2 & 129.6 & 248.0 & 13.3 & 198.0 & 202.6 & 28.7 & 6.7 & 3.9 & 14.2 & 4.5 & 4.7 & 6.1 & 20.0 & 1.1 & 0.022 & 0.590 \\
\hline VI & 86.3 & 131.9 & 258.7 & 16.2 & 236.6 & 256.0 & 35.2 & 6.2 & 4.4 & 13.9 & 3.9 & 7.0 & 5.5 & 21.3 & 1.1 & 0.017 & 0.677 \\
\hline VII & 86.0 & 132.3 & 258.1 & 15.7 & 153.7 & 257.7 & 39.3 & 6.1 & 4.3 & 15.3 & 5.5 & 2.2 & 7.0 & 21.4 & 1.2 & 0.019 & 0.050 \\
\hline VIII & 87.1 & 130.9 & 255.0 & 16.3 & 264.4 & 272.8 & 40.0 & 6.5 & 4.6 & 14.6 & 4.0 & 6.1 & 6.0 & 20.8 & 0.9 & 0.016 & 0.796 \\
\hline IX & 87.9 & 131.9 & 252.6 & 16.4 & 208.4 & 268.7 & 31.8 & 6.4 & 4.1 & 11.9 & 3.9 & 7.3 & 6.0 & 19.9 & 0.9 & 0.018 & 0.500 \\
\hline X & 88.3 & 128.0 & 251.2 & 10.9 & 212.1 & 143.9 & 22.4 & 5.7 & 3.7 & 15.6 & 5.4 & 2.3 & 4.7 & 21.4 & 1.2 & 0.015 & 0.325 \\
\hline General & 86.9 & 131.3 & 255.4 & 14.5 & 201.7 & 215.2 & 30.2 & 6.3 & 4.0 & 14.2 & 4.4 & 4.8 & 5.8 & 20.6 & 1.1 & 0.019 & 0.710 \\
\hline Mean & & & & & & & & & & & & & & \\
\hline
\end{tabular}

DF: Days to flowering, DM: Days to maturity, PH: Plant height (cm), NB: Number of branches per plant, NP: Number of pods per plant, BIOL: Biological yield per plant (g), HI: Harvest index (\%), SW: 100-seeds weight (g), NS: Number of seeds per pod, CP: Crude protein (\%), CF: Crude fiber (\%), Met: Methionine (mg per g of protein), Try: Tryptophan (mg per g of protein), Tan: Tannin (mg per g), SY: Seed yield per plant (g). 
Fig.1

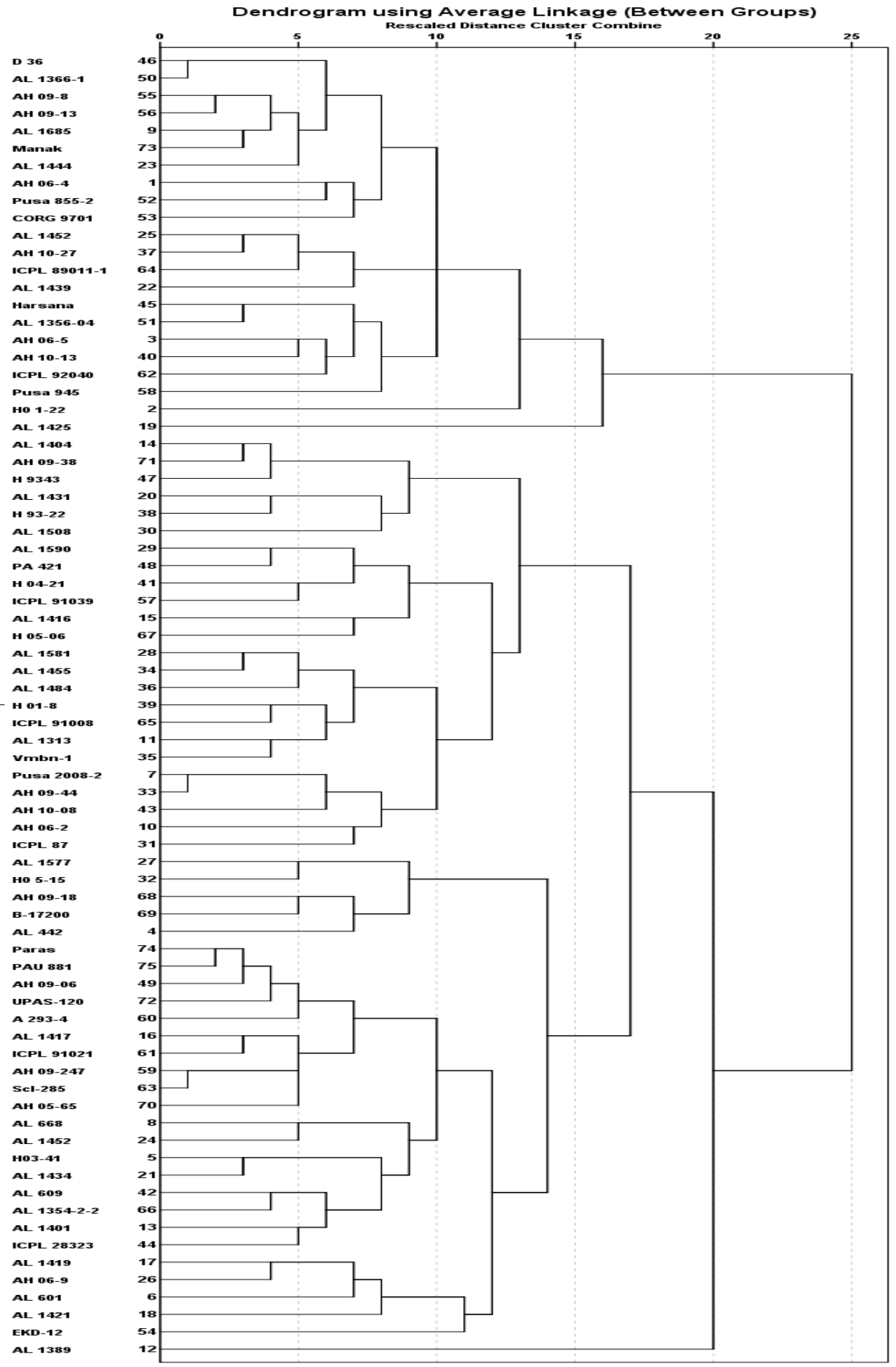


From the study, it was evident that genotypes under cluster $\mathrm{X}$ showed highest mean values for days to $50 \%$ flowering, harvest index and crude protein content and lowest for days to maturity, number of branches per plant, biological yield per plant, 100 seed weight, crude fibre and tryptophan content. Genotypes of cluster IX showed highest mean value for number of branches per plant and fat content and lowest for harvest index and methionine content. Genotypes under cluster VIII showed highest mean value for number of pods per plant, biological yield per plant, seed yield per plant and number of seed per pod and lowest for methionine content. Genotype of cluster VII showed highest mean value for ash, crude fibre and crude protein content and lowest for days to $50 \%$ flowering and tannin content. Genotypes under cluster V showed highest mean value for 100 seed weight and lowest for plant height. Genotypes of cluster IV showed highest mean value for days to maturity and lowest for methionine content. Genotype of cluster II showed highest mean value for plant height, methionine, tryptophan and tannin content and lowest for number of pods per plant, seed yield per plant, number of seed per pod, fat content and crude protein content.

Based on yield and quality traits studied, the genotypes viz., AL1404, AL1356-04, ICPL 89011-1, H 93-43, AH 09-38, AL1389, AL 668, ICPL 91039, AH 06-4 and AL 609 were found genetically diverse and superior. The present study was intended to examine the genetic diversity for yield and quality traits, will be of great use and will serve as a stepping stone in formulation and effective execution of future breeding programmes in pigeonpea. To initiate a systematic breeding programme and to develop pigeonpea varieties with combination of high seed yield and quality the above specified genotypes should be used in pigeonpea breeding programmes for further improvement.
From the findings of present investigation, it could be concluded that the 75 pigeonpea genotypes differed significantly for all yield and quality traits. The maximum inter cluster distance was observed between cluster II (H 01-22) and cluster VIII (AL 1404, AL 1431, AL 1508, H 93-22, $\mathrm{H}$ 93-43 and AH 09-38) followed by between cluster II and cluster VI and cluster II and cluster IX. Based on yield and quality traits studied, the genotypes viz., AL 1404, AL 1356-04, ICPL 89011-1, H 9343, AH 09-38, AL 1389, AL 668, ICPL 91039, AH 06-4 and AL 609 showed sufficient genetic diversity and contrasting characters and these can be used in pigeonpea breeding programmes for further improvement.

\section{References}

Aruna, T. and Devindra, S. (2016). Nutritional and anti- nutritional characteristics of two varieties of pigeonpea (Cajanus cajan L.) seeds. International Journal of Scientific and Research Publications, 6(9): 567-572.

Birhan, T., Zeleke, H., Ayana, A., Tilahun A. and Chemeda, A. (2013). Genetic variability, heritability and genetic advance in early maturing pigeonpea (Cajanus cajan L.) genotypes. World Journal of Agricultural Sciences, 1(7): 241-247.

Durga, K.K., Rao, Y.K. and Reddy, M.V. (2005). Genetic divergence in chickpea (Cicer arietinum L.). Legume Research, 28(4): 250-255.

Dwevedi, K.K. and Gaibriyal, M. (2009). Assessment of genetic diversity of cultivated chickpea (Cicer arietinum L.). Asian Journal of Agricultural Sciences, 1: 7-8.

Kumar, B.N., Dharmaraj, P.S. and Wali,V.B. (2004). Genetic diversity and variability studies of advanced breeding lines of pigeonpea (Cajanus cajan L). IJAPBC, 3(2): $2277-4688$.

Lokere, Y.A., Patil, J.V. and Chavan, U.D. (2007). Genetic analysis of yield and quality traits in Kabuli chickpea. Journal of Food Legumes, 20(2): 147-149. 
Navneet, S., Sikarwar, R.S., Singh, A.K and Kumar, A. (2017). Genetic diversity in pigeonpea (Cajanus cajan L). International Journal of Agriculture Sciences, pp. 41774179.

Nwokolo, E. (1986). Nutritional evaluation of pigeonpea meal. Plant Foods for Human Nutrition, 37(4): 283-290.

Odeny, D.A. Jayashree, B., Ferguson, M., Hoisington, D. and Cry, L.J. (2007). Development, characterization and utilization of microsatellite markers in pigeonpea. Plant Breeding.126:130-136.

Pandey, P., Kumar, R., Pandey, V.R. and Tripathi, M. (2013). Genetic divergence studies in pigeonpea (Cajanus cajan L.). American Journal of Plant Sciences, 4: 2126-2130.

Rana, J.C., Gautam, N. K., Gayacharan, Singh, M., Yadav, R. Tripathi, K., Yadav, S.K., Panwar, N.S. and Bhardwaj, R. (2016). Genetic resources of pulse crops in India: An overview. Indian Journal of Geneicst, 76(4): 420-436.

Rao, P.J.M., Upender, M. and Bhaskar, A.V. (2013). Variability and genetic diversity studies in pigeonpea (Cajanus cajan L.). International journal of applied biology and pharmaceutical technology, 4(4): 09764550.

Reddy, V.G., Jayalakshmi, V. and Sreenivas, T. (2015). Genetic divergence studies in pigeonpea inbreds lines. Electronic Journal of Plant Breeding, 6(2): 515-520.

Reddy, V.G., Jayalakshmi, V. and Sreenivas, T. (2015). Genetic divergence studies in pigeonpea inbreds lines. Electronic Journal of Plant Breeding, 6(2): 515-520.

Saxena, K. B. Kumar, R. and Sultana (2010). Quality nutrition through Pigeonpea a review health, 2(11): 1335-1344.
Saxena, K.B. (2008). Genetic Improvement of Pigeonpea- A Review. Tropical Plant Biology. 1:159-178.

Saxena, K.B., Saxena, R.K., Kumar, R.V. and Varshney, R.K. (2008). Evidence of a unique inter-allelic epistatic interaction for seed coat color in pigeonpea (Cajanus cajan L.). Euphytica, 186(3): 813-816.

Shweta and Srivastava, A. (2013). Genetic diversity in germplasm of pigeonpea. Asian Journal of Bio Science, 8(2): 218-220.

Sinha, S.K. (1977). Food and Agriculture Organization, Rome, pp. 1-102.

Sreelakshmi, Ch., Kumar, C.V.S. and Shivani, D. (2011). Genetic analysis for yield and its components in hybrid pigeonpea. Electronic Journal of Plant Breeding, 2(3): 413-416.

Sreelakshmi, Ch., Shivani, D. and Kumar, C.V.S. (2010). Genetic divergence and stability analysis in pigeonpea (Cajanus cajan L.). Electronic Journal of Plant Breeding, 1(4): 530-535.

Vijayalakshmi, P., Anuradha, Ch., Pavankumar, D., Sreelaxmi, A. and Anuradha, G. (2013). Path coefficient and correlation response for yield attributes in pigeonpea (Cajanas cajan L.). International Journal of Scientific and Research, 3(4): 2250-3153.

Yadav, A.K., S.B., Singh, S.S. and Madhuri, A. (2010). Character association and genetic divergence study in chickpea (Cicer arietinum L.). Enviournment and Ecology, 28(2B): 1276-1280.

Yang, S., Ash, G., Harper, J., Varling, J. and Wenzl, P. (2006). Low level of genetic diversity in cultivated pigeonpea compared to its wild relatives is revealed by diversity arrays technology. Theoretical and Applied Genetics. 113: 585-595.

\section{How to cite this article:}

Yogesh, Ravika, Rajesh Yadav, Nisha Kumari and Suman. 2019. Genetic Diversity for Quality Traits and Seed Yield in Pigeonpea [Cajanus cajan (L.) Millsp.]. Int.J.Curr.Microbiol.App.Sci. 8(06): 2837-2844. doi: https://doi.org/10.20546/ijcmas.2019.806.342 